\title{
Dam Flood Prevention through Data Analysis using Automatic Control System
}

\author{
M. Kavitha ${ }^{1 *}$, V. Senthil Nayagam ${ }^{2}$, S. Jayaprakash ${ }^{3}$, S. Nirmalraj ${ }^{4}$, \\ M. Sharmila ${ }^{5}$, N. Allimalar 6 \\ \{kaveem@gmail.com, sensribala@gmail.com, jakash2109@gmail.com, snirmalraj4u@gmail.com, \\ sharmilamuralidharan1200@gmail.com, allimalar99@gmail.com \} \\ Assistant Professor ${ }^{1-4}$, Sathyabama Institute of Science and Technology, Chennai, India \\ UG Student $^{5-6}$, Sathyabama Institute of Science and Technology, Chennai, India
}

\begin{abstract}
This project deals improved dam water management mechanism. The flood which is caused due to sudden release of dam water is prevented by continuously monitoring the dam and transporting the water from one dam to another if necessary. People in the world get affected because of flood in winter and water scarcity in summer. Reservoir is the most efficient tool to save the water resources. The water in reservoirs can be used for domestic and industrial purpose, irrigation, hydropower generation, navigation, ecology, boating, fishing and other forms of recreational activities. But it gets wasted in the form flood. Hence a prototype is constructed more efficiently to save the life of people and environment from flood impacts and also to save the water resources. It is a low cost automated control system which provides better accuracy. Here the data is analyzed and controlled by Arduino Uno R3. This automatic control system is completely programmed. The data is communicated from one dam to another dam through master controller and the communication between the master controller and dams takes place wirelessly using RF Transmitters/Receivers. The master controller has an LCD display to output visual information.
\end{abstract}

Keywords: Dam Flood Control, Arduino Uno R3, RF Transmitters, RF Receivers.

\section{Introduction}

Flooding is a natural phenomenon that has gained global attention as a result of its adverse impact on the society. It results in tremendous environmental destruction and loss of lives. Many recent floods in the country have been caused by the sudden drainage of water from the dam. Sudden release of significant quantities of water from reservoirs causes floods in the low-lying areas. Data compiled from the reports of South Asia Network on Dams, Rivers and People (SANDRP) is shown in Fig. 1. Sudden floods from dams without warning in advance lead to a failure to relocate nearby residents which results in high mortality rates To avoid such complications water level in dams need to be monitored effectively and it is necessary to create an alert to people when the water level increases from the normal capacity. This is generally performed manually which is very inefficient and requires full time supervision by more number of operators [1]. Embedded system has become an integral part of Engineering design process. From data processing to hardware work, it is of great interest everywhere because of its reliability and time bound perfection. The ESP8266 microcontroller and sensors are used for detecting water level and creating alert to people. It is achieved 
through the application SWOD (Save Water Overflow Detection). With the help of microcontroller unit (MCU) PIC18F452, the liquid sensors and GSM technology can establish a remote water level alarm system. But these microcontrollers make the system costlier and complex.

An Arduino is an open-source, easy to use hardware and software based electronics platform. It is more versatile and cheap compared to the microcontrollers. The Flood Observatory and Warning system is fully automated device which uses Arduino and alerts the authorities and people using SMS [2] and voice alert system which is fixed the centralized location of the village. But this system is less accurate and must require Wi-Fi network. It just creates alert to the people but it is not capable of managing the dam gates. The incorrect opening and closing of the dam gate also leads to overflow of water which causes flood. This method of controlling the dam gates is handmade but has many drawbacks. The dam gate system which is Arduino oriented [3] is more reliable and feasible due to low cost and it also gives better performance than microcontroller [4] - [9] or PLC.

These researches have explained the importance of automatic dam gate control system and the early detection and alert system of flood disaster. But the aftermath of flood not only results in loss of lives, it also damages the crops, homes, buildings and water resources. The Rule Curve, practiced internationally, is a dam operating schedule. It governs when and how a dam should be filled or drained, and ensures that the dam is completely full only by the end of monsoon and it is absolutely dry by summer.

This paper aims in preventing the flood by monitoring and managing the dam water more efficiently to save the life of people and environment from flood impacts and also to save the water resources. It presents an improved dam water management mechanism using Arduino Uno R3 which is programmed. This software is written in C language and output can be tested either on LCD display or on laptop by connecting USB cable to the controller board. It is a low cost automated control system which provides better accuracy.

\section{Proposed System Description}

Fig. 2 shows the block diagram of Dam flood prevention through data analysis using automatic control system. This block diagram is designed considering three dams and one master controller. Each dam architecture contains an Arduino Uno to which an ultrasonic sensor, keypad, $12 \mathrm{~V}$ adapter, transmitter and receiver is interfaced. It also contains a $12 \mathrm{~V} \mathrm{DC}$ pump motor which is interfaced to the Arduino Uno board through transistor. Here the transistor acts as the switch. The master controller contains an Arduino Uno to which an LCD display, transmitter and receiver is interfaced. The Arduino Uno board gets powered from the $9 \mathrm{~V}$ battery. It is a microcontroller board based on the ATmega328 which is programmed. It controls the features of the devices interfaced to it.

The proposed system is designed considering that the rainfall is near Dam-1 area and the same procedure is applicable for all cases. The ultrasonic sensor which is fixed at the crest of Dam-1 measures the current water level (in liters) in the dam. The value of upcoming water (in liters) due to rain near Dam-1 area is sent as input via keypad. The value of current water 
level and upcoming water gets added up and gives the value of total water (in liters). This value is compared with the total capacity (in liters) of the Dam-1. If the total water is lesser than the Dam-1 capacity then the upcoming water from rain will automatically gets stored into the Dam-1 itself. If the total water is greater than the Dam-1 capacity then Dam-1 cannot hold the upcoming water because it leads to overflowing. This data is communicated to master controller and from master controller to Dam-2. Here communication takes place wirelessly with the help of transmitters and receivers. The Dam-2 receives the data and checks whether its capacity is greater than the total water. If yes then it responds "Yes" to the master controller and Dam-1 motor runs to pump water from Dam-1 to Dam-2. Then Dam-1 becomes free to hold the upcoming water. Else it responds "No" to the master controller then master controller communicates the data to Dam-3 and the same process continues for $n$ number of dams. If all the dams are full then the water can be diverted to sea. The LCD display in master controller is used to output visual information.

\section{Flood of mismanagement}

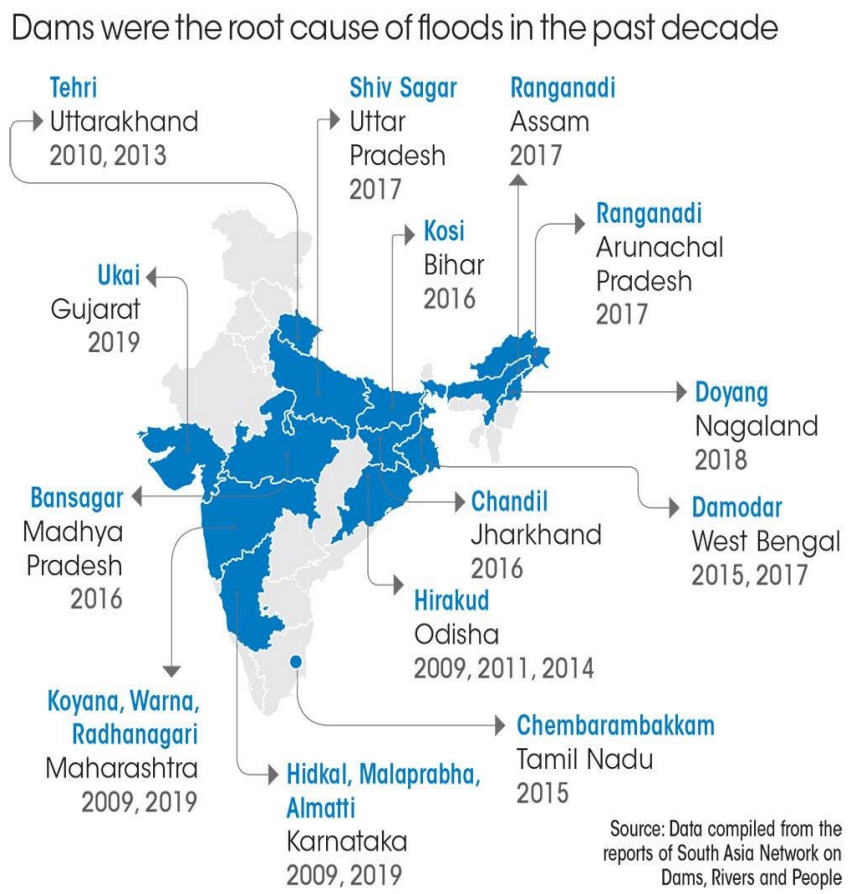

Fig.1. Flood of Mismanagement

Fig.3 illustrates the overall operation of the proposed system. This explanation is as same as the block diagram explanation. Fig.4, 5 and 6 illustrates the Dam-1, master controller and Dam-2 operation respectively through a flowchart. 


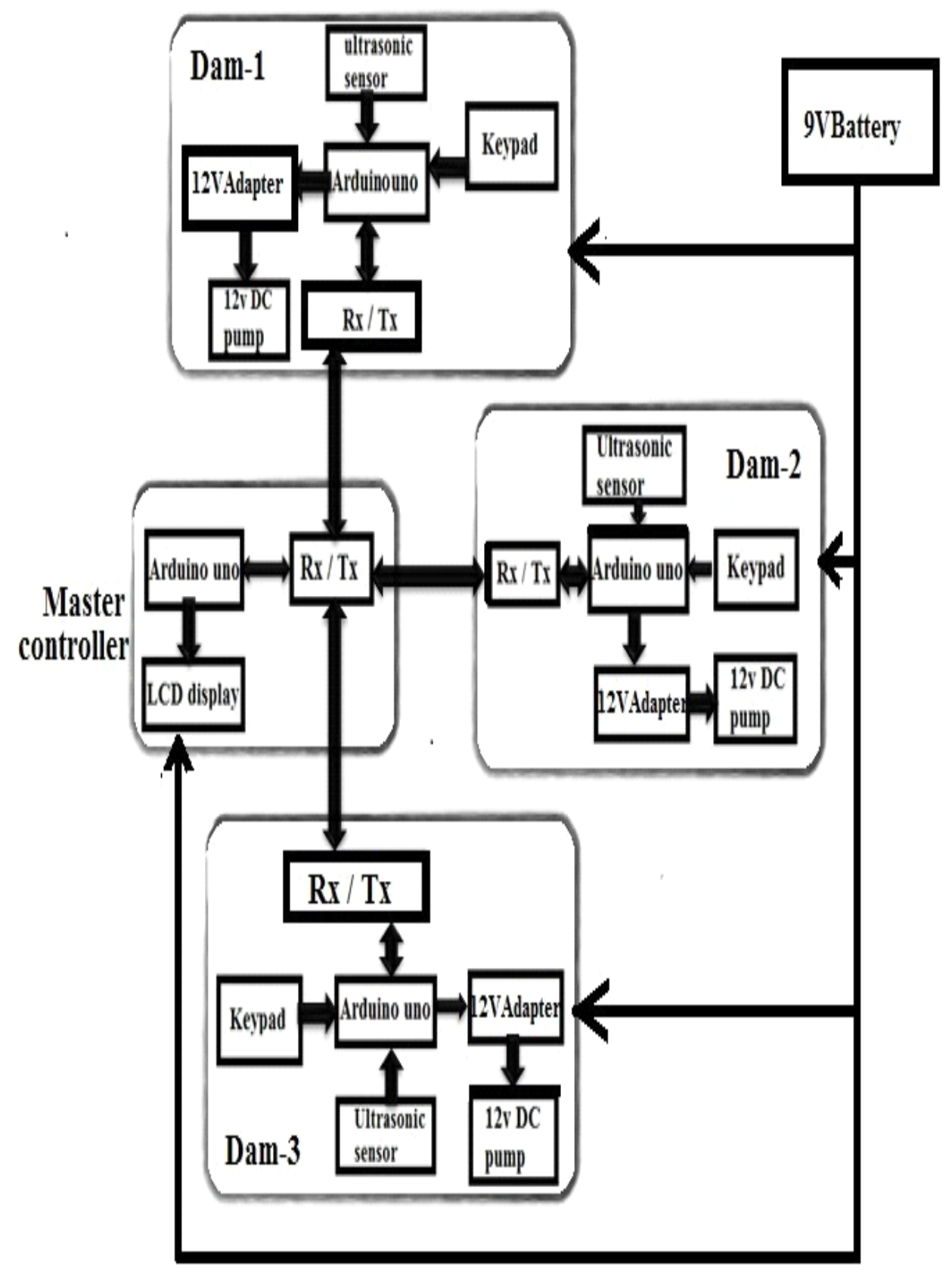

Fig. 2. Block diagram 


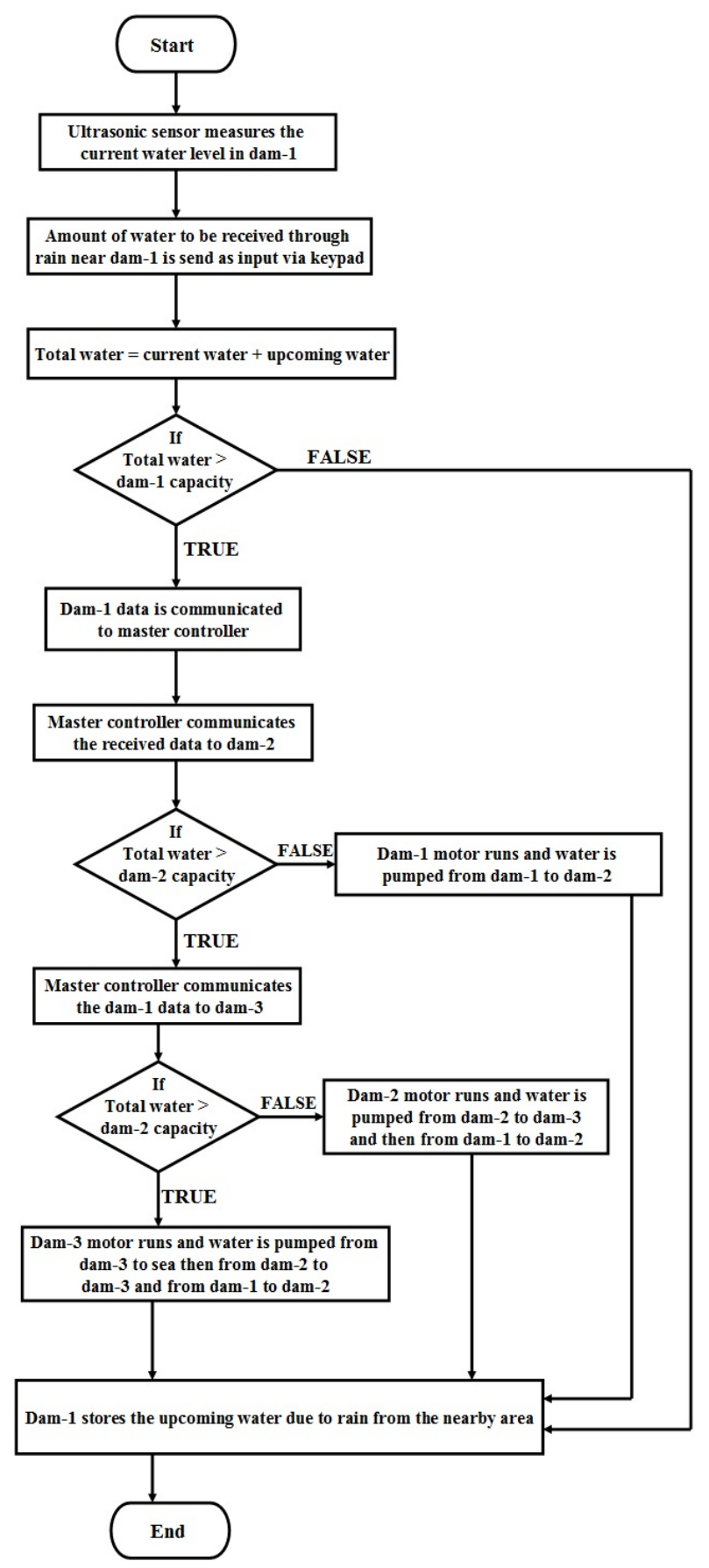

Fig. 3. Overall flowchart 


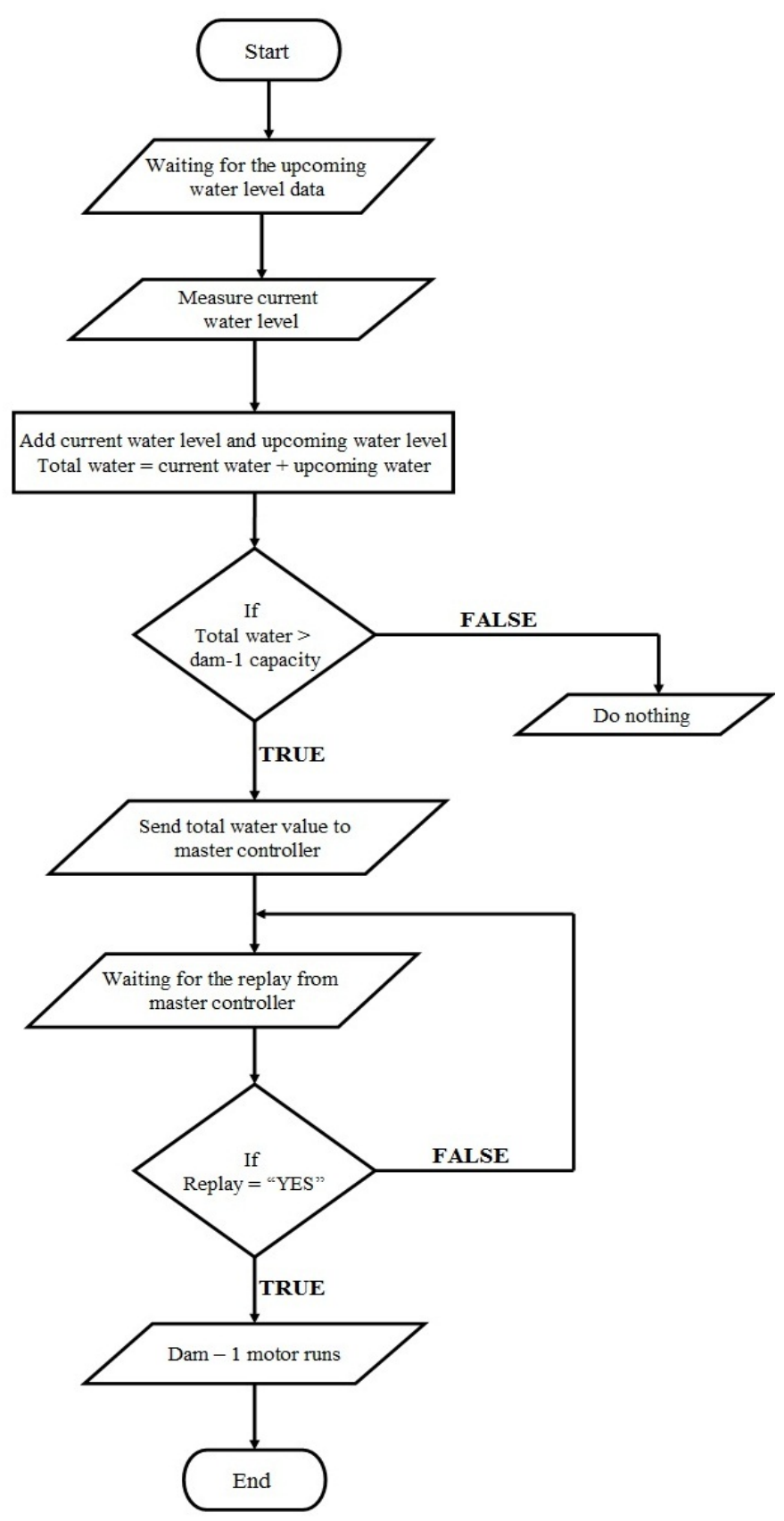

Fig. 4. Dam-1 flowchart 


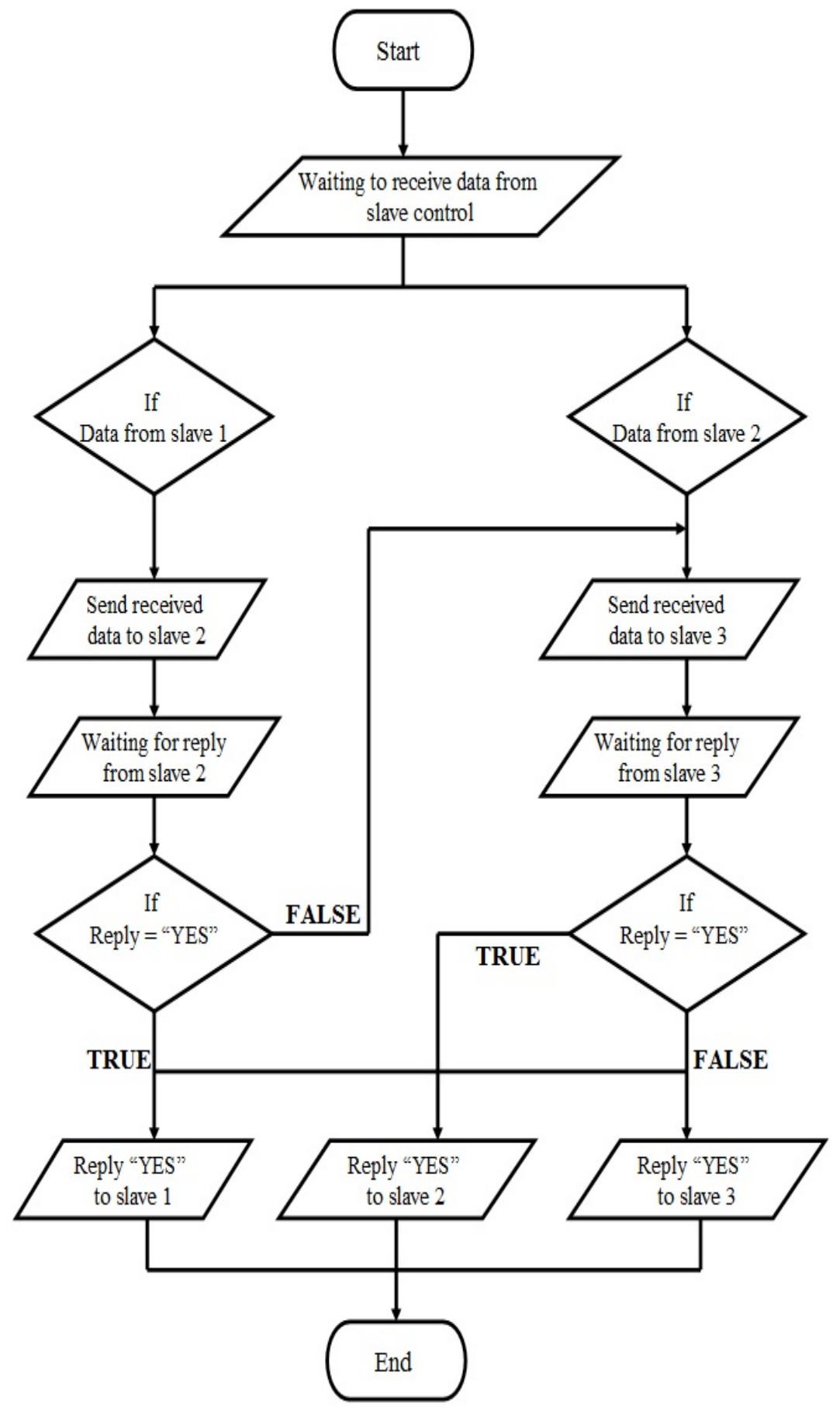

Fig. 5. Master controller flowchart 


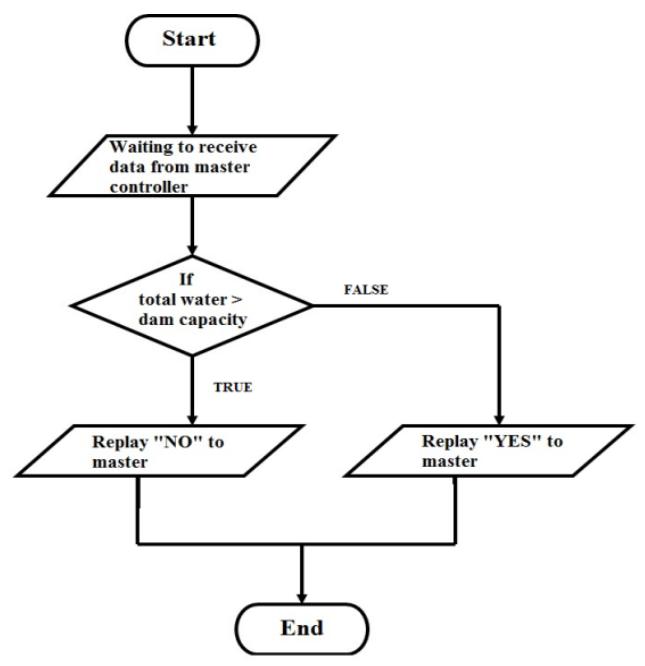

Fig. 6. Dam-2 flowchart

\section{Hardware Description}

The circuit diagram of Dam-1, Master controller and Dam-2 is shown separately in Fig.7, 8 and 9 respectively as there are no wired connections between them and the communication takes place wirelessly.

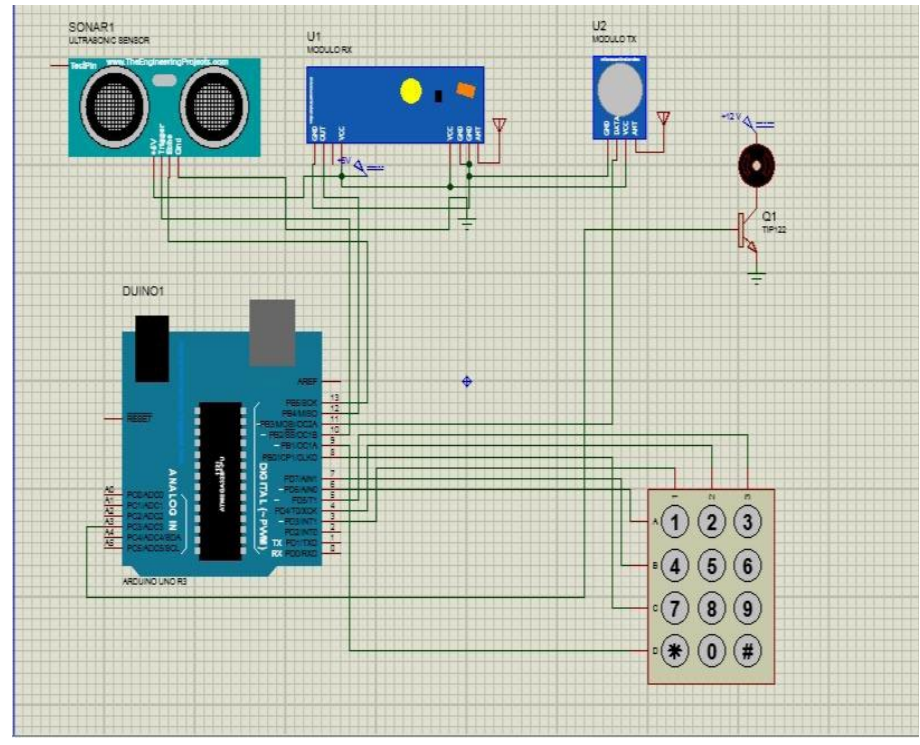

Fig. 7. Dam-1 circuit diagram 
The Dam-1 circuit diagram in Fig.7 has an Arduino Uno R3 to which an ultrasonic sensor, keypad, transistor, transmitter and receiver is interfaced. It also contains a $12 \mathrm{~V} \mathrm{DC}$ pump motor which is interfaced to the Arduino board through transistor. It is driven by a $12 \mathrm{~V}$ DC power supply from an adapter where the transistor acts as the switch. A 9V DC input is given to Arduino board with help of a battery. It gets powered and starts controlling the features of the devices interfaced to it. It is a microcontroller board based on the ATmega328 which is programmed. The ultrasonic sensor measures the current water level (in liters) in the dam. The value of upcoming water (in liters) due to rain near Dam-1 area is sent as input via keypad. This value is calculated earlier through weather forecast reports which can reliably predict the weather approximately 90 percent of the time in 7 days advance. The value of current water level and upcoming water gets added up and gives the value of total water (in liters). This value is compared with the total capacity (in liters) of the Dam-1which is already set in the program. If the total water is lesser than the Dam-1 capacity then the motor does not run which means the Dam-1 can hold the upcoming water from rain without overflowing. If the total water is greater than the Dam-1 capacity then the data is communicated to next dam through the master controller. The motor starts running and pumps the water to the next dam once it receives the comment "Yes" from the master controller. Here the communication takes place wirelessly via transmitter and receiver.

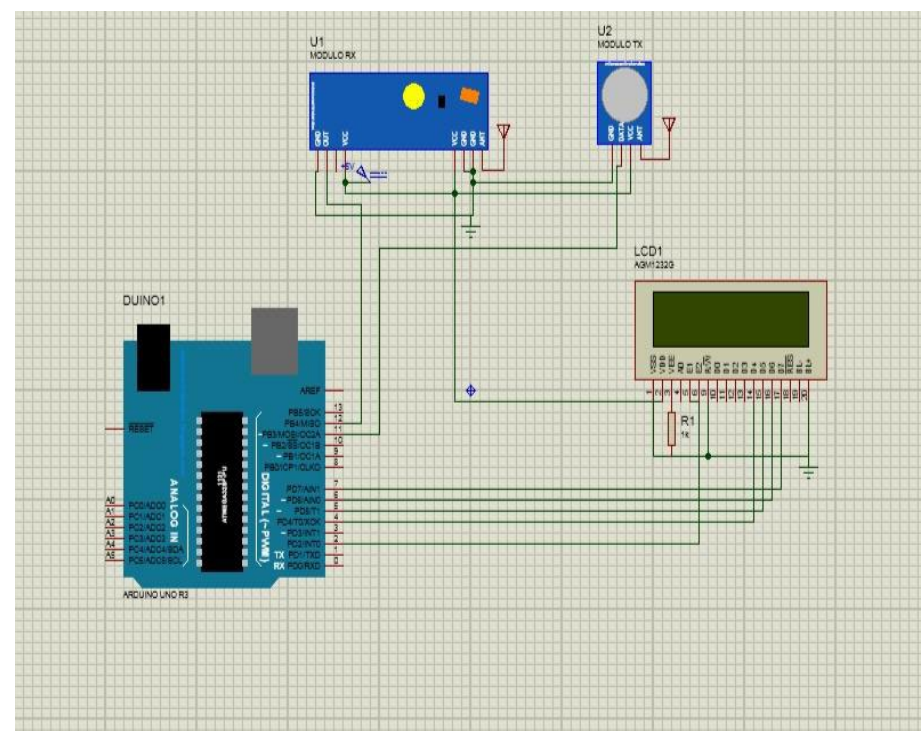

Fig. 8. Master controller circuit diagram

The master controller circuit diagram in Fig.8 has an Arduino Uno R3 to which LCD display, transmitter and receiver is interfaced. The Arduino gets powered and starts controlling the features of the devices interfaced to it. The transmitter with receiver is used for communication with the dams. Once it receives the total water data from Dam1 it communicates the data to Dam-2 and then to other consecutive dam until it receives the comment "Yes". After receiving the comment it communicates with the Dam-1. The LCD display is used to output the step- by -step visual information. 


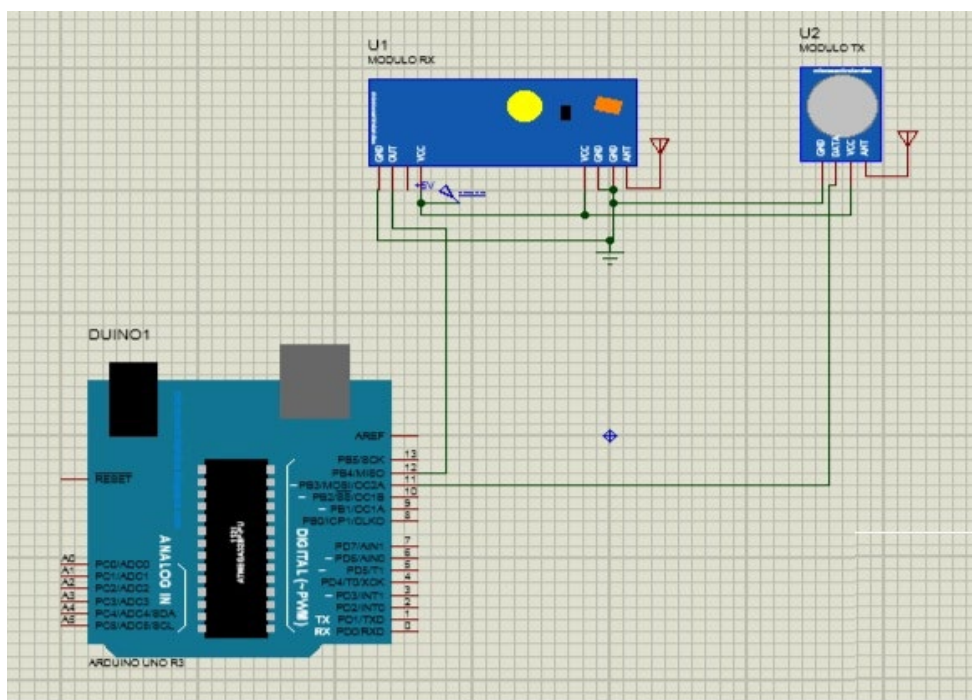

Fig. 9. Dam-2 circuit diagram

The Dam-2 circuit diagram in Fig.9 contains an Arduino Uno R3 to which a transmitter and receiver is interfaced. Since the proposed system is designed considering that the rainfall is near Dam1 area the Dam2 circuit diagram is simple. It just receives the total water value of Dam1 from master controller and checks whether its total capacity (in liters) can hold the water if yes it responds "Yes" to the master controller else it responds "No".

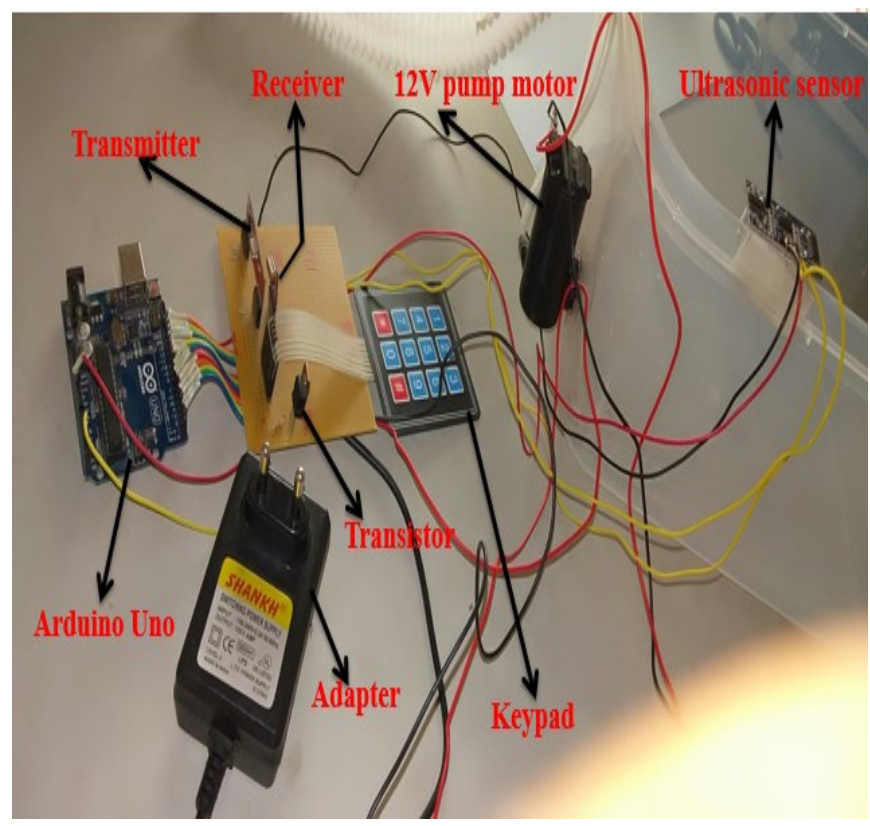

Fig.10 Hardware Circuit of Dam-1 

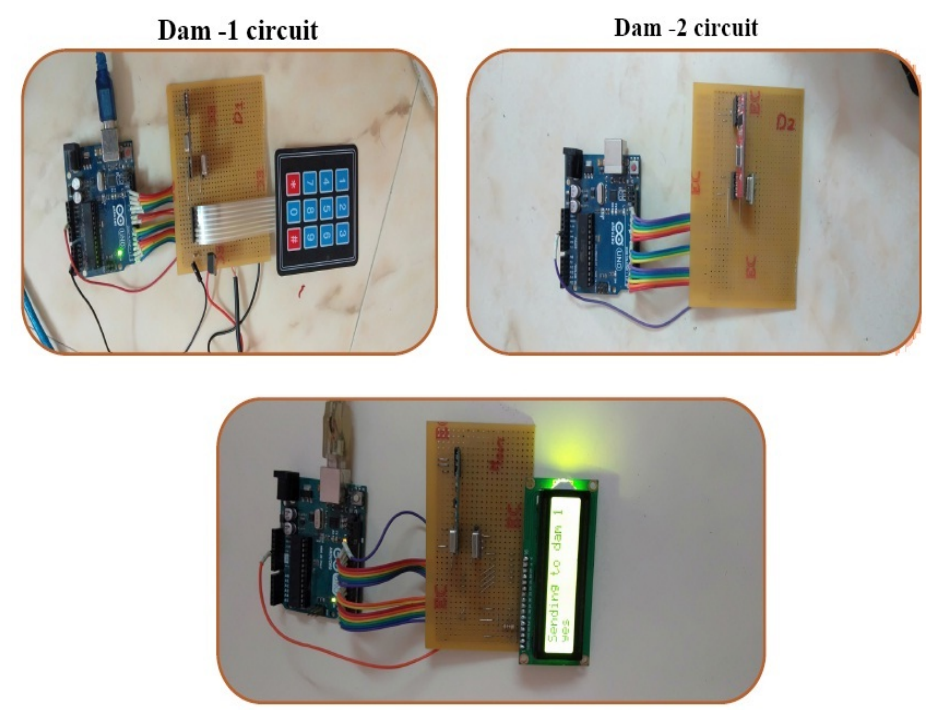

Master controller circuit

Fig. 11. Hardware Circuit of Dam-1, Dam-2 and Master Controller

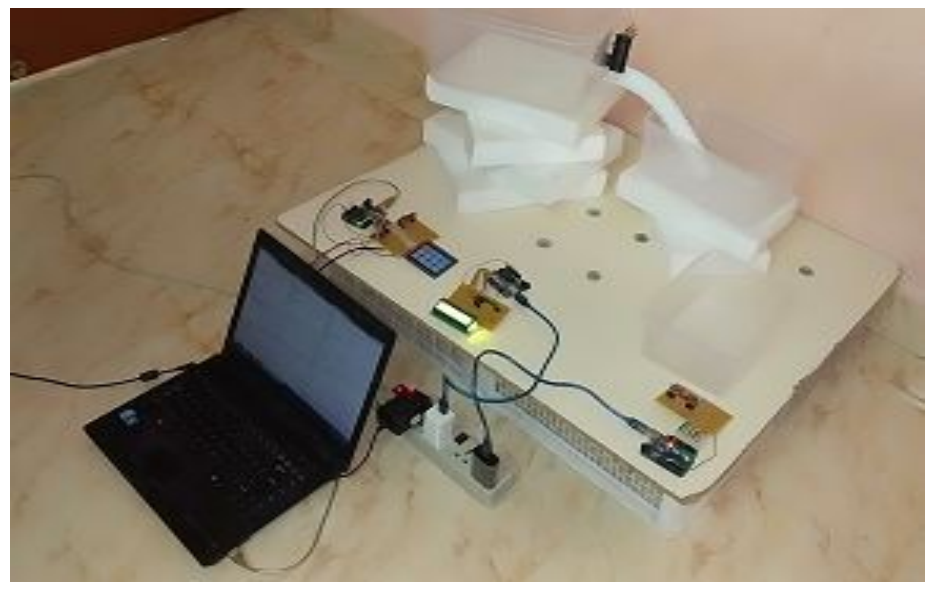

Fig. 12. Overall Prototype

Fig.10 shows the hardware parts of the Dam-1. Fig.11 shows the hardware circuit of Dam -1, Dam-2 and master controller. Fig. 13 shows the laptop output of all three controllers. 


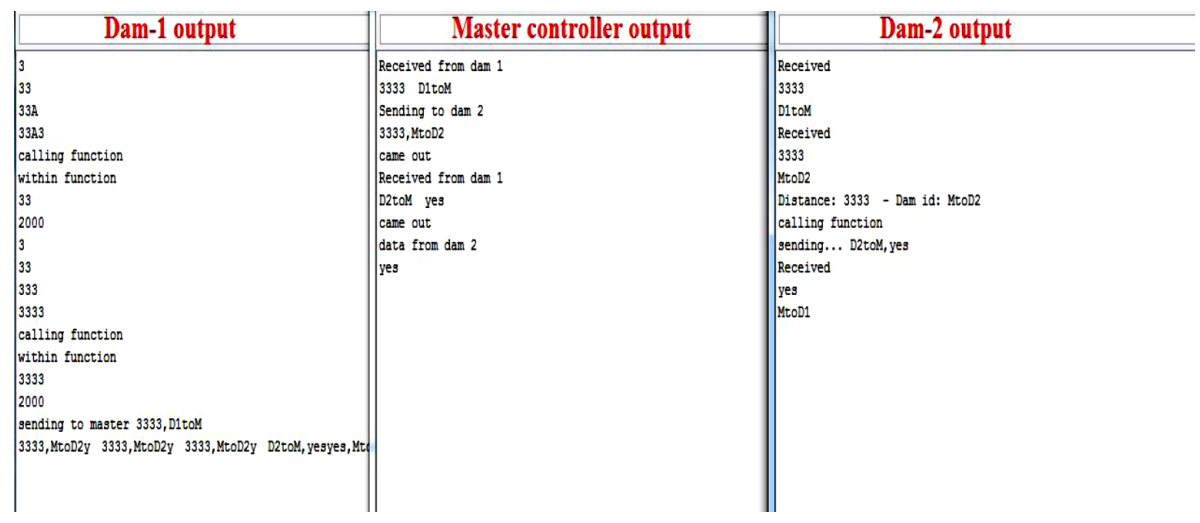

Fig. 13. Programmed output

\section{Conclusion}

In this project, an improved dam water management mechanism has been proposed. It is a low cost automated control system which provides better accuracy. By this method the flood which is caused due to sudden release of dam water is prevented by continuously monitoring the dam and transporting the water from one dam to another if necessary. Here the data is analyzed by the Arduino Uno R3 which is programmed. This software is written in C language and output is tested on laptop or LCD display. It is more efficient method and communication between dams takes place wirelessly using Transmitters/Receivers. This project can be implemented in future as a completely automated system. The input data which is given through the keypad can be directly accessed from the satellites and the communication between the dams is also possible using satellites. Since satellites ensure long distance communication more accurately it can be used instead of Transmitter/Receiver.

\section{References}

[1] Thekkil, Tibin Mathew, and N. Prabakaran. "Real-time WSN based early flood detection and control monitoring system." In2017 International Conference on Intelligent Computing, Instrumentation and Control Technologies (ICICICT), pp. 1709-1713. IEEE, 2017.

[2] Jagadeesh Babu Mallisetty and Chandrasekhar V. "Internet of Things Based Real Time Flood Monitoring and Alert Management system." In 2018 International Journal of Pure and Applied Mathematics, pp. 859-868. 2018.

[3] May Thwe Oo, and Thin Thin. "Gate Control System of Dam using Programmable Logic Controller." In 2019 International Journal of Research and Scientific Innovation (IJRSI), pp. ISSN 2321-2705. IJRSI, May 2019.

[4] Iyer, Makesh, Shrikant Pai, Sneha Badri, and Shubhangi Kharche. "Embedded Dam Gate Control System using'C'and Visual Basic." International Journal of Computer Applications69, no. 2 (2013).

[5] Kavitha, M., and V. Sivachidambaranathan. "New Improved Two-Phase Interleaved Converter with Clamp Circuit and Diode Capacitor cell." Microprocessors and Microsystems (2020): 103035.

[6] Jayaprakash, S., R. Ramani, M. Kavitha, and V. Senthil Nayagam. "Comparison of solar based closed loop DC-DC converter using PID and ANN control for shunt motor drive."International Journal of Power Electronics and Drive Systems10, no. 3 (2019): 1324. 
[7] Nayagam, V. Senthil, and L. Premalatha. "Green energy based coupled inductor interleaved converter with MPPT technique for BLDC application." International Journal of Power Electronics and Drive Systems 9, no. 4 (2018): 1725.

[8] Kavitha, M., and V. Sivachidambaranathan. "High-Voltage Gain DC-DC Converter for Renewable Energy Applications." InCognitive Informatics and Soft Computing, pp. 657-669. Springer, Singapore, 2020.

[9] Illavarason, P, Arokia Renjith J, Mohan Kumar, P 2019, 'Evaluating the Effectiveness of Visual Techniques Methodologies for Cerebral Palsy Children and Analyzing the Global Developmental Delay', Springer, Lecture Notes in Electrical Engineering, vol 521, pp 99-105. 